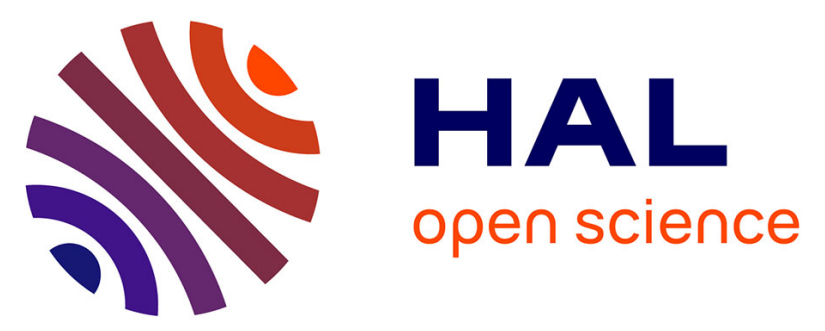

\title{
A joint model for longitudinal and time-to-event data to better assess the specific role of donor and recipient factors on long-term kidney transplantation outcomes
} Marie-Cécile Fournier, Yohann Foucher, Paul Blanche, Fanny Buron, Magali Giral, Etienne Dantan

\section{To cite this version:}

Marie-Cécile Fournier, Yohann Foucher, Paul Blanche, Fanny Buron, Magali Giral, et al.. A joint model for longitudinal and time-to-event data to better assess the specific role of donor and recipient factors on long-term kidney transplantation outcomes. European Journal of Epidemiology, 2016, 31 (5), pp.469-479. 10.1007/s10654-016-0121-2 . hal-01443463

\author{
HAL Id: hal-01443463 \\ https://hal.science/hal-01443463
}

Submitted on 21 Sep 2021

HAL is a multi-disciplinary open access archive for the deposit and dissemination of scientific research documents, whether they are published or not. The documents may come from teaching and research institutions in France or abroad, or from public or private research centers.
L'archive ouverte pluridisciplinaire HAL, est destinée au dépôt et à la diffusion de documents scientifiques de niveau recherche, publiés ou non, émanant des établissements d'enseignement et de recherche français ou étrangers, des laboratoires publics ou privés. 
A joint model for longitudinal and time-to-event data to better assess the specific role of donor and recipient factors on long-term kidney transplantation outcomes.

Marie-Cécile Fournier ${ }^{1,2}$, Yohann Foucher ${ }^{1}$, Paul Blanche ${ }^{3}$, Fanny Buron ${ }^{4}$, Magali Giral ${ }^{2,5}$, Etienne Dantan ${ }^{1 *}$

${ }^{1}$ EA4275 SPHERE - bioStatistics, Pharmacoepidemiology and Human sciEnces REsearch, Nantes University,

* Corresponding author : EA4275 - SPHERE,

1 rue Gaston Veil, 44035 Nantes, France

Tel.: +33-(0)2.40.41.28.24

Fax: +33-(0)2.40.41.29.96

Etienne.Dantan@univ-nantes.fr

${ }^{2}$ Institut de Transplantation Urologie Néphrologie (ITUN), Nantes University Hospital, Labex Transplantex, Inserm U1064, Nantes, France

${ }^{3}$ Department of biostatistics, University of Copenhagen, Denmark

${ }^{4}$ Service de Néphrologie, Transplantation et Immunologie Clinique, Hôpital Edouard Herriot, Lyon, France

${ }^{5}$ Centre d'investigation clinique biothérapie, Nantes, France 


\begin{abstract}
Background In renal transplantation, serum creatinine ( $\mathrm{SCr}$ ) is the main biomarker routinely measured to assess patient's health, with chronic increases being strongly associated with longterm graft failure risk (death with a functioning graft or return to dialysis). Joint modeling may be useful to identify the specific role of risk factors on chronic evolution of kidney transplant recipients: some can be related to the $\mathrm{SCr}$ evolution, finally leading to graft failure, whereas others can be associated with graft failure without any modification of SCr.

Methods Sample data for 2749 patients transplanted between 2000 and 2013 with a functioning kidney at 1-year post-transplantation were obtained from the DIVAT cohort. A shared random effect joint model for longitudinal SCr values and time to graft failure was performed.

Results We show that graft failure risk depended on both the current value and slope of the SCr. Deceased donor graft patient seemed to have a higher SCr increase, similar to patient with diabetes history, while no significant association of these two features with graft failure risk was found. Patient with a second graft was at higher risk of graft failure, independent of changes in SCr values. Anti-HLA immunization was associated with both processes simultaneously.

Conclusion Joint models for repeated and time-to-event data bring new opportunities to improve the epidemiological knowledge of chronic diseases. For instance in renal transplantation, several features should receive additional attention as we demonstrated their correlation with graft failure risk was independent of the SCr evolution.
\end{abstract}

Keywords: joint modeling; time-to-event data; repeated measurements; serum creatinine; graft failure; kidney transplantation. 


\section{INTRODUCTION}

Recently, Asar et al. (1) pointed out that joint models for repeated and time-to-event data should be used to correctly consider longitudinal and survival processes and their relationship when they are strongly dependent $(2,3)$. Joint models could allow identification of specific associations for each risk factor: 1) association with an event risk, 2) association with an event risk throughout a previous marker evolution modification, and 3) associations on both longitudinal and survival processes. With this type of suitable model, the precise description of specific associations could provide new insights in the knowledge of a disease pathway mechanism.

Indeed, from a methodological standpoint, longitudinal measurements and time-to-event data are typically analyzed separately, using a mixed model and survival model respectively, without considering their possible relationship (2). However, it is known that these two processes are often mutually dependent in a chronic disease context. Inferences from mixed models may be biased in cases of an informative censoring process (4-6). Similarly, the time-dependent Cox model fails to correctly handle a time-dependent endogenous variable, which is a variable generated by the patient themselves (e.g. creatinine) in contrast to an exogenous variable which is not (e.g. air pollution level) (7-9). It also often fails to correctly account for measurement error.

In many chronic diseases, the occurrence of major events and the assessment of corresponding risk factors guide physicians in implementing the most beneficial care for patients. In renal transplantation, serum creatinine ( $\mathrm{SCr}$ ) is a well-known longitudinal marker used to assess the health of kidney transplant recipients especially after the first year post-transplantation, i.e. in the chronic phase of the disease evolution (10). In the chronic phase, graft failure, defined as return to dialysis or death with a functioning graft, is often preceded by a continuous deterioration in renal function and is associated with an irreversible increase in $\mathrm{SCr}$ levels. In contrast, during the first year post-transplantation, patients are submitted to a risk of early graft failure due to acute clinical events such as delayed graft function, acute rejection episode, and infections or complications. Therefore the disease evolution mechanism is very different between the acute 
and chronic phases $(11,12)$. Few authors have studied the association of risk factors on renal function evolution $(13,14)$ while the risk factors associated with long-term graft failure have been well described $(12,15,16)$. Renal function has been shown to be one of the most important risk factors $(17,18)$. However, the precise mechanism is not well known: the majority of risk factors leading to graft failure may be associated with chronic SCr changes, finally leading to graft failure, but one can also hypothesize that some features may be related to graft failure risk independently from their association on SCr evolution.

Whilst several authors have used joint models for longitudinal and time-to-event data in renal transplantation (19-22), none have precisely studied the specific association of each baseline explicative variable. The precise study of such associations would be of primary importance for physicians in order to improve their appraisal of kidney transplant recipients' health. Therefore, we present for the first time a shared random effect multivariable joint model to study the baseline characteristics that could be related to long-term kidney graft outcomes. By studying $\mathrm{SCr}$ evolution and graft failure from one year post-transplantation, it brings an epidemiological approach to understand the risk factors associated with the disease evolution in its chronic phase.

\section{MATERIALS AND METHODS}

\section{Study population}

Data were extracted from the French observational and prospective DIVAT cohort (www.divat.fr) of kidney transplant recipients from 6 University hospitals (French Research Ministry: RC12_0452, last agreement No 13 334, No CNIL for the cohort: 891735, No CNIL for the study: 914226). According to the following inclusion criteria, 2749 patients were studied: adult recipients who received a first or second renal transplant between January 2000 and August 2013 from a living or heart beating deceased donor, alive with a functioning graft at 1year post-transplantation and maintained under Tacrolimus and Mycofenolic acid. All study participants gave informed consent. 


\section{Available data}

Most classical risk factors susceptible to influence $\mathrm{SCr}$ evolution and/or graft failure risk were extracted from the database. Donor features included: age, gender, last SCr level, deceased (from cardiovascular cause vs other) / living donation. Recipient characteristics were: age, gender, Body Mass Index (BMI), history of comorbidities (diabetes, hypertension, dyslipidemia, neoplasia, cardiovascular), duration of dialysis before transplantation, preemptive graft, hemodialysis or peritoneal dialysis, pre-transplant anti-class I or class II Human Leucocyte Antigen (HLA) immunization and cause of initial renal disease (recurrent nephropathy or not). Transplantation parameters were: cold ischemia time and number of HLA-A-B-DR incompatibilities. The following variables were collected within the first year posttransplantation: occurrence of delayed graft function (defined as the need for dialysis after transplantation), occurrence of acute rejection episodes and SCr levels at 3 and 6 months posttransplantation.

\section{Outcomes}

The baseline was the 1-year post-transplantation anniversary. The best marker of renal function should be the measured GFR (mGFR) (23). Unfortunately, this measurement is costly and is not performed in practice for routine patient follow-up. Different equations to estimate GFR (eGFR) have been proposed (24-27), and are principally based on $\mathrm{SCr}$ values adjusted on recipient age, gender and ethnicity. A major limitation lies in the fact that these eGFR formulae have been developed from general population data or from patients with chronic kidney disease and thus may not be applicable to kidney transplant patients (28-30). Despite this, SCr or eGFR are equivalent in terms of relative evolution, the second resulting from a transformation of the first parameter. We decided to study the $\mathrm{SCr}(\mu \mathrm{mol} / \mathrm{L})$, which was the longitudinal marker routinely recorded yearly until patient death with a functioning graft or return to dialysis. The time-toevent (graft failure) was defined as the delay between 1-year post-transplantation and the first event between return to dialysis or death with a functioning graft. 


\section{Statistical analysis}

We used a shared random effect model. It combines a mixed model for the longitudinal process and a parametric survival model for the time-to-event process, for which underlying hypotheses were checked in an independent manner. For the longitudinal assessment, we used a logarithmic transformation of $\mathrm{SCr}$ values in order to respect both assumptions related to residual's homoscedasticity and linear relationship over time. Two random effects were considered for the baseline value and the slope. For survival, hazard proportionality and log-linearity were assessed. In a joint shared random effect framework, longitudinal and survival processes are linked through common random effects. Rizopoulos has previously described the possible parameterizations to model this dependence (2). For instance, the survival process can be modeled as dependent on the current level of the marker, on the intensity of marker evolution (i.e. the slope), on both current level and slope, on cumulative effects or on lagged effects.

In the first step of model building, we defined a baseline risk function and the dependence between the two processes from a joint model without baseline explicative variables. We graphically retained a Weibull distribution for the baseline risk function. According to the Bayesian Information Criteria (BIC), the dependence between the two processes was characterized by the instantaneous hazard of graft failure depending on both the level and the slope of the longitudinal marker at the current time. As recommended by Rizopoulos to solve optimization difficulties, all quantitative variables were standardized in order to scale the coefficients (2).

In the second step, we performed the selection of baseline explicative variables. Univariable models were composed using three effects of each variable: on baseline value, on the slope (interaction with time) and on the graft failure risk. Among these parameters, those which were not significant $(p>0.05)$ were removed in a hierarchical manner: if the association on the slope was significant, the corresponding association on baseline value was also considered. Finally, a multivariable joint model was generated by including effects retained in the univariable models, and a forward stepwise selection was performed (always using a 5\% type-I error rate). 
In order to study the relevance of the joint modeling, we also performed separate analyses: i) a linear mixed model to study the SCr evolution and ii) a time-dependent Cox model to study the graft failure risk. We used the same variables selection procedure.

As sensitivity analyses, we performed two joint models in a cause specific approach: i) time-toreturn to dialysis by censoring death, and in contrast ii) time-to-death with a functioning graft by censoring return to dialysis.

Joint model parameters were estimated by likelihood maximization. The complete mathematical formulation of the joint model is shown in appendix 1. Due to the logarithmic transformation of $\mathrm{SCr}$, coefficients for the longitudinal process have an interpretation as relative change rather than absolute change. Details related to interpretations are presented in appendix 2. Confidence intervals for relative change were obtained using parametric simulations (5 000 iterations) (31). All analyses were performed using the 3.0.1 version of the R software (32) with the 1.3-0 version of the JM package (33).

\section{RESULTS}

\section{Baseline characteristics}

Baseline characteristics are presented in Table 1. Sixty percent of the recipients were male, with a mean age of $49.7 \pm 13.6$ years. Histories of cardiovascular disease or dyslipidemia were observed in one third of recipients, $11.6 \%$ had history of diabetes, $82.6 \%$ had hypertension, and $8.3 \%$ had a cancer before the transplantation. Second transplantations were realized in $17.2 \%$ of studied patients. Immunologic characteristics included: $12.8 \%$ of patients presented more than 4 HLA-A-B-DR incompatibilities, and around one third were immunized against class I or class II HLA prior to transplantation. Donors were mainly deceased $(84.8 \%)$ with a mean age of $50.7 \pm 15.5$ years and $56.4 \%$ were male. Delayed graft function occurred for 714 patients (26.1\%). SCr at 3 and 6 months were on average $138.3 \pm 53.4$ and $136.6 \pm 53.2 \mu \mathrm{mol} / \mathrm{L}$ respectively. Finally, $21.5 \%$ of recipients presented at least one episode of acute rejection before the first anniversary of the graft. 


\section{Follow-up description}

During follow-up, 278 patients returned to dialysis and 203 died with a functioning graft. The median event-free follow-up time was 3.99 years. The patient-graft survival curve and its corresponding 95\% confidence interval (95\%CI) are presented in Figure 1. Patient-graft survival rates at 10 years after the first anniversary of the graft was $58.4 \%$ [95\%CI: $54.8 \% ; 62.3 \%$ ]. Additionally, 12843 SCr measurements were collected, with a median of 4 measurements per patient (ranging from 1 to 14 ). The median time between two measurements was 11.7 months (interquartile range: $9.2,12.5$ ).

\section{Joint modeling}

Table 2 presents the estimations related to the final multivariable joint model.

\section{Dependence between SCr dynamic and graft failure risk}

For any time one year after transplantation $(t>1)$, the graft failure risk depended on both the current value and the current slope of the SCr. If a patient had a $25 \%$ higher SCr, graft failure risk was twice as high $(\mathrm{HR}=1.92,95 \% \mathrm{CI}$ : $[1.75 ; 2.11])$. Moreover, for a given SCr value, where a patient had a steeper increase in SCr graft failure risk was significantly worse (HR=1.89, 95\%CI: [1.17; 3.06]_for an increase of $25 \%$ in $\mathrm{SCr}$ value in one year).

Factors associated with 1-year post-transplantation $\mathrm{SCr}$

Several factors appeared significantly correlated with a higher 1-year SCr without significant association with the SCr evolution or with graft failure risk. An increase of $50 \mu \mathrm{mol} / \mathrm{L}$ in the 6month SCr level was associated with a 1-year $\mathrm{SCr}$ increase of $17.99 \%$ (95\%CI: $[16.62 \% ; 19.34 \%])$. Patient with a graft provided from a donor ten years older compared to other donor had a 3.68\% higher SCr at 1 year (95\%CI: [2.97\%; 4.39\%]).

Factors associated with SCr evolution during follow-up

A history of diabetes was associated with a higher SCr increase. After 5 years, the presence of this comorbidity for a patient was associated with a $\mathrm{SCr} 14.45 \%$ higher (95\%CI: $[7.76 \% ; 21.46 \%])$ compared to its absence, while we did not observe any significant 
difference at 1 year. For a given patient, a graft from a deceased donor due to a cerebrovascular cause was associated with a relative increase of $12.52 \%$ in expected 5-year $\mathrm{SCr}$ (95\%CI: $[6.50 \% ; 18.89 \%])$, compared to a graft from a living donor, but only a $7.14 \%$ increase when compared to a deceased donor due to another cause (95\%CI: [1.48\%; $13.00 \%])$.

Factors associated with both 1-year post-transplantation SCr and SCr evolution during the follow-up Male recipient had a $7.68 \%$ higher 1-year SCr (95\%CI: [5.83\% ; 9.51\%]). Nevertheless, he was likely to have a slower increase: after 5 years follow-up the gap reduced to $3.98 \%$ (95\% CI: $[0.18 \% ; 7.81 \%])$.

\section{Factors associated with the graft failure risk}

Two factors were significantly associated with graft failure risk. Without significant correlation with the SCr, a patient transplanted for the second time had a higher graft failure risk compared to his first transplantation $(\mathrm{HR}=1.32,95 \% \mathrm{CI}$ : $[1.02 ; 1.73])$. On the contrary, for a given patient, graft from male tended to be associated with a smaller risk of graft failure compared to graft from female donor $(\mathrm{HR}=0.83,95 \% \mathrm{CI}:[0.69 ; 1.01])$.

Factors associated with both $\mathrm{SCr}$ and the graft failure processes

A 10-year older patient was associated with a $2.04 \%$ lower 1-year SCr (95\%CI: $[1.31 \% ; 2.77 \%])$. Moreover, this difference increased during the follow-up, ie $5.57 \%$ lower at 5 years post-transplantation (95\%CI: $[4.20 \% ; 6.95 \%])$. This could be explained by lower creatinine production in the elderly population due to a smaller muscle mass. However, for a given $\mathrm{SCr}$ evolution during the follow-up, the situation where the recipient is older was associated with a higher graft failure risk $(\mathrm{HR}=1.35$ for a 10-year older patient, 95\%CI: $[1.25 ; 1.46])$.

For a given patient, higher 3-month $\mathrm{SCr}$ was associated with a significantly higher 1-year $\mathrm{SCr}$ level. For instance, for a $50 \mu \mathrm{mol} / \mathrm{L}$ difference at 3-months, the 1-year SCr level increased by $8.08 \%$ (95\%CI: [6.83 ; 9.32]). Additionally, for a given evolution of SCr from 1-year posttransplantation, a higher 3-month $\mathrm{SCr}$ was associated with a lower graft failure risk $(\mathrm{HR}=0.85$ for an increase of $50 \mu \mathrm{mol} / \mathrm{L}$ in 3-month SCr level, 95\%CI: [0.75;0.95]). 
Major risk factors included acute rejection in the first year post-transplantation, immunization, and cardiovascular history. When a patient had an acute rejection episode during the first year post-transplantation, a 5.65\% higher 1-year SCr was observed compared to cases where no acute rejection occurred $(95 \% \mathrm{CI}$ : $[3.65 ; 7.71])$. Nevertheless, independently of the current value and the slope of SCr, the situation where acute rejection has occurred appeared with a higher risk of graft failure $(\mathrm{HR}=1.46,95 \% \mathrm{CI}:[1.17 ; 1.83])$. A patient with cardiovascular history was more likely to have an increased SCr compared to the same patient without this history, and a higher graft failure risk independently from this increase (HR=1.39, 95\%CI: $[1.14 ; 1.69])$. Similarly, a significant SCr increase was demonstrated for pre-transplant immunized patient, with an additional graft failure risk not related to this SCr increase, compared to the same patient nonimmunized.

\section{Separate models}

The linear mixed model estimations and those of the time-dependent Cox model are presented in tables 3 and 4 respectively. One can note differences in the retained variables. An acute rejection episode in the first year post-transplantation was significantly associated with the SCr evolution by using a linear mixed model, in opposition to the results obtained by using joint models. No relationship between cardiovascular history or donor type with $\mathrm{SCr}$ evolution were retained by using the linear mixed model, while we concluded from the final joint model that patients with cardiovascular history may have a significantly higher SCr increase during the follow-up ( $\mathrm{p}=$ 0.0371) and SCr evolution could be different given the donor type status $(\mathrm{p}=0.0022)$. Slight underestimations of hazard ratios were obtained from the time-dependent Cox model compared to the joint model. For example, the hazard ratio related to the recipient age was 1.25 (95\% CI [1.19-1.38]) for 10 years older by using the time-dependent Cox model against 1.35 (95\% CI $[1.25 ; 1.46])$ by using the joint model. Additionally, diabetes was retained as a risk factor for graft failure by using the Cox model, while it does not by using the joint model. In 
contrast, acute rejection episode was not retained as a risk factor for graft failure by using the time-dependent Cox model, while it was by using the joint model.

\section{Cause specific approach}

Using a cause specific approach (tables S1 and S2 in supplementary materials), we observed that current $\mathrm{SCr}$ level was more importantly associated with return to dialysis (HR=2.51, 95\%CI $[2.22 ; 2.84])$ compared to death with a functioning graft $(\mathrm{HR}=1.47$, 95\%CI $[1.24 ; 1.74])$. As expected, this higher association was also observed for acute rejection episode $(\mathrm{HR}=1.63,95 \% \mathrm{CI}[1.20 ; 2.20]$ versus $\mathrm{HR}=1.24$, 95\%CI $[0.86 ; 1.80])$. In contrast, cardiovascular history $(\mathrm{HR}=1.07,95 \% \mathrm{CI}[0.81 ; 1.41]$ versus $\mathrm{HR}=2.01,95 \% \mathrm{CI}[1.49 ; 2.70])$ and recipient age $(\mathrm{HR}=1.20,95 \% \mathrm{CI}[1.05 ; 1.39]$ versus $\mathrm{HR}=2.36,95 \% \mathrm{CI}[1.95 ; 2.86])$ were strongly associated with the time-to-death.

\section{DISCUSSION}

Our results show that during the chronic phase of renal transplantation, elevated SCr levels as well as the magnitude of $\mathrm{SCr}$ increases are associated with a higher risk of graft failure. Accordingly, physicians routinely supervise both the current $\mathrm{SCr}$ level and its increase. The large majority of baseline explicative variables are firstly associated with the baseline SCr level or its evolution, finally leading to graft failure. Interestingly, we demonstrated that besides the association of cardiovascular history with increased SCr, this risk factor was additionally associated with an increase in the risk of graft failure. Therefore, at a given time for a given $\mathrm{SCr}$ level and slope, the presence of cardiovascular history should be considered as a risk factor for graft failure. Similarly, patient transplanted for a second time seemed at higher risk of graft failure, regardless of the SCr level or its slope, compared to its first graft. Other factors independent of SCr leading to increased graft failure risk may result from stronger immunosuppression or undetected immunization against donor specific antigens. In addition to 
retransplantation or the presence of cardiovascular history, particular attention should also be paid to patients with a high 3-month SCr level, transplantation in older patients or when an acute rejection episode during the first year has occurred. These patients may be more susceptible to graft failure without having previously displayed aberrant $\mathrm{SCr}$ levels. On the contrary, if a patient received a deceased donor graft but had a SCr evolution analogous to those which would be observed if the graft had come from a living donor, the monitoring of this patient should be the same regardless of the donor status.

In renal transplantation, numerous studies have focused on only one or two measurements of renal function to study their association with graft failure (34-36). However, the joint modeling approach allows the whole trajectory of longitudinal SCr measurements to be taken into account. In this paper, we used for the first time a shared random effect joint modeling to more precisely specify the association between chronic SCr evolution and graft failure risk. Different types of dependence can be considered such as the current marker level, the evolution intensity during the follow-up, cumulative effects or lagged effects (2).

More generally, our approach illustrates that joint modeling constitutes a powerful approach for time-to-event analysis with endogenous time-dependent variable (1), which supports a real mechanistic evolution for many chronic diseases. However, their use in observational studies is still uncommon. As previously acknowledged by Asar et al. (1), differing results and interpretations between the joint modeling and the separate approaches reinforce the necessity to use joint modeling in the presence of endogenous variable. We also highlighted the differences in our application in kidney transplantation. In other diseases, the informative censoring or the endogenous nature for the longitudinal variable can result in even higher differences.

One limitation in our study may be the graft failure definition: the first event between the return to dialysis and death with a functioning graft. Because it is very difficult to distinguish the cause of death related or not to the disease, we performed a sensitivity analyses. The results illustrated the overall robustness of the results but with a probable underestimation of the association between the $\mathrm{SCr}$ and the acute rejection episode on the risk of graft failure. 
In conclusion, our results illustrate the importance of joint models and their potential usefulness in improving chronic disease research. It brings a more complete epidemiological view of the risk factors and the related natural disease history mechanisms. The use of this novel statistical model on a large cohort of kidney transplant recipients highlights that several risk factors were associated with $\mathrm{SCr}$ evolution while others were associated with graft failure risk independently of the initial SCr value or its subsequent evolution. These included elderly or immunized recipients, second transplantations, grafts coming from female donors, patients experiencing an acute rejection episode in the first year post-transplantation, patients with cardiovascular history or with a high gap between 3 and 12 month $\mathrm{SCr}$ measurements, features that should receive additional attention.

\section{ACKNOWLEDGEMENTS}

We wish to thank the DIVAT scientific board (C Legendre, H Kreis, L Rostaing, N Kamar, E Morelon, G Mourad, V Garrigue, M Kessler and M Ladrière) as well as members of the clinical research assistant team (S Le Floch, A Petit, J Posson, C Scellier, V Eschbach, K Zurbonsen, C Dagot, F M'Raiagh, V Godel, X Longy and P Przednowed). The DIVAT cohort is partially supported by Roche Laboratory since 1994.

Conflict of Interest: The authors declare that they have no conflict of interest. 


\section{REFERENCES}

1. Asar Ö, Ritchie J, Kalra PA, Diggle PJ. Joint modelling of repeated measurement and time-to-event data: an introductory tutorial. Int J Epidemiol. févr 2015;44(1):334 - 44.

2. Rizopoulos D. Joint Models for Longitudinal and Time-to-Event Data: With Applications in R. CRC Press; 2012. 279 p.

3. Wulfsohn MS, Tsiatis AA. A joint model for survival and longitudinal data measured with error. Biometrics. mars 1997;53(1):330-9.

4. Leffondre K, Boucquemont J, Tripepi G, Stel VS, Heinze G, Dunkler D. Analysis of risk factors associated with renal function trajectory over time: a comparison of different statistical approaches. Nephrol Dial Transplant Off Publ Eur Dial Transpl Assoc - Eur Ren Assoc. août 2015;30(8):1237-43.

5. Ibrahim JG, Molenberghs G. Missing data methods in longitudinal studies: a review. Test Madr Spain. 1 mai 2009;18(1):1-43.

6. Tsiatis AA, Davidian M. joint modeling of longitudinal and time-to-event data: an overview. Stat Sin. 2004;(14):809-34.

7. Rizopoulos D, Takkenberg JJM. Tools \& techniques--statistics: Dealing with time-varying covariates in survival analysis--joint models versus Cox models. EuroIntervention J Eur Collab Work Group Interv Cardiol Eur Soc Cardiol. juin 2014;10(2):285-8.

8. Andrinopoulou E-R, Rizopoulos D, Jin R, Bogers AJJC, Lesaffre E, Takkenberg JJM. An introduction to mixed models and joint modeling: analysis of valve function over time. Ann Thorac Surg. juin 2012;93(6):1765-72.

9. Kalbfleisch JD, Prentice RL. The Statistical Analysis of Failure Time Data. John Wiley \& Sons; 2011. 464 p.

10. Levey AS, Coresh J, Balk E, Kausz AT, Levin A, Steffes MW, et al. National Kidney Foundation practice guidelines for chronic kidney disease: evaluation, classification, and stratification. Ann Intern Med. 15 juill 2003;139(2):137-47.

11. Galichon P, Xu-Dubois Y-C, Finianos S, Hertig A, Rondeau E. Clinical and histological predictors of long-term kidney graft survival. Nephrol Dial Transplant Off Publ Eur Dial Transpl Assoc - Eur Ren Assoc. juin 2013;28(6):1362-70.

12. Foucher Y, Daguin P, Akl A, Kessler M, Ladriere M, Legendre C, et al. A clinical scoring system highly predictive of long-term kidney graft survival. Kidney Int. 2010;78(12):1288 $-94$.

13. Ferro CJ, Hodson J, Moore J, McClure M, Tomson CRV, Nightingale P, et al. Bayesian analysis of glomerular filtration rate trajectories in kidney transplant recipients: a pilot study. Transplantation. mars 2015;99(3):533-9. 
14. Marcén R, Morales JM, Fernández-Rodriguez A, Capdevila L, Pallardó L, Plaza JJ, et al. Long-term graft function changes in kidney transplant recipients. NDT Plus. juin 2010;3(Suppl_2):ii2-8.

15. Pascual M, Theruvath T, Kawai T, Tolkoff-Rubin N, Cosimi AB. Strategies to improve long-term outcomes after renal transplantation. N Engl J Med. 21 févr 2002;346(8):58090 .

16. Debout A, Foucher Y, Trébern-Launay K, Legendre C, Kreis H, Mourad G, et al. Each additional hour of cold ischemia time significantly increases the risk of graft failure and mortality following renal transplantation. Kidney Int. févr 2015;87(2):343-9.

17. de Bruijne MHJ, Sijpkens YWJ, Paul LC, Westendorp RGJ, van Houwelingen HC, Zwinderman $\mathrm{AH}$. Predicting kidney graft failure using time-dependent renal function covariates. J Clin Epidemiol. mai 2003;56(5):448-55.

18. Kasiske BL, Andany MA, Danielson B. A thirty percent chronic decline in inverse serum creatinine is an excellent predictor of late renal allograft failure. Am J Kidney Dis Off J Natl Kidney Found. avr 2002;39(4):762-8.

19. Daher Abdi Z, Essig M, Rizopoulos D, Le Meur Y, Prémaud A, Woillard JB, et al. Impact of longitudinal exposure to mycophenolic acid on acute rejection in renal-transplant recipients using a joint modeling approach. Pharmacol Res Off J Ital Pharmacol Soc. juin 2013;72:52-60.

20. Moranne O, Maillard N, Fafin C, Thibaudin L, Alamartine E, Mariat C. Rate of renal graft function decline after one year is a strong predictor of all-cause mortality. Am J Transplant Off J Am Soc Transplant Am Soc Transpl Surg. mars 2013;13(3):695-706.

21. Rizopoulos D, Ghosh P. A Bayesian semiparametric multivariate joint model for multiple longitudinal outcomes and a time-to-event. Stat Med. 30 mai 2011;30(12):1366-80.

22. Garre FG, Zwinderman AH, Geskus RB, Sijpkens YWJ. A joint latent class changepoint model to improve the prediction of time to graft failure. J R Stat Soc Ser A Stat Soc. 1 janv 2008;171(1):299-308.

23. Stevens LA, Coresh J, Greene T, Levey AS. Assessing kidney function--measured and estimated glomerular filtration rate. N Engl J Med. 8 juin 2006;354(23):2473-83.

24. Levey AS, Stevens LA, Schmid CH, Zhang YL, Castro AF 3rd, Feldman HI, et al. A new equation to estimate glomerular filtration rate. Ann Intern Med. 5 mai 2009;150(9):60412.

25. Levey AS, Bosch JP, Lewis JB, Greene T, Rogers N, Roth D. A more accurate method to estimate glomerular filtration rate from serum creatinine: a new prediction equation. Modification of Diet in Renal Disease Study Group. Ann Intern Med. 16 mars 1999;130(6):461-70.

26. Nankivell BJ, Gruenewald SM, Allen RD, Chapman JR. Predicting glomerular filtration rate after kidney transplantation. Transplantation. 27 juin 1995;59(12):1683-9. 
27. Cockcroft DW, Gault MH. Prediction of creatinine clearance from serum creatinine. Nephron. 1976;16(1):31-41.

28. Buron F, Hadj-Aissa A, Dubourg L, Morelon E, Steghens J-P, Ducher M, et al. Estimating glomerular filtration rate in kidney transplant recipients: performance over time of four creatinine-based formulas. Transplantation. 15 nov 2011;92(9):1005-11.

29. White CA, Akbari A, Doucette S, Fergusson D, Knoll GA. Estimating Glomerular Filtration Rate in Kidney Transplantation: Is the New Chronic Kidney Disease Epidemiology Collaboration Equation Any Better? Clin Chem. 2010;56(3):474-7.

30. Gaspari F, Ferrari S, Stucchi N, Centemeri E, Carrara F, Pellegrino M, et al. Performance of different prediction equations for estimating renal function in kidney transplantation. Am J Transplant Off J Am Soc Transplant Am Soc Transpl Surg. nov 2004;4(11):182635.

31. Aalen OO, Farewell VT, De Angelis D, Day NE, Gill ON. A Markov model for HIV disease progression including the effect of HIV diagnosis and treatment: application to AIDS prediction in England and Wales. Stat Med. 15 oct 1997;16(19):2191-210.

32. R Development Core Team . R: A Language and Environment for Statistical Computing [Internet]. Computing RF for S, éditeur. Vienna, Austria; 2010. Disponible sur: http://www.R-project.org/

33. Rizopoulos D. JM: An R Package for the Joint Modelling of Longitudinal and Time-toEvent Data. J Stat Softw. 2010;35(9).

34. Kasiske BL, Israni AK, Snyder JJ, Skeans MA, Peng Y, Weinhandl ED. A simple tool to predict outcomes after kidney transplant. Am J Kidney Dis Off J Natl Kidney Found. nov 2010;56(5):947-60.

35. Lenihan CR, O’Kelly P, Mohan P, Little D, Walshe JJ, Kieran NE, et al. MDRD-estimated GFR at one year post-renal transplant is a predictor of long-term graft function. Ren Fail. 2008;30(4):345-52.

36. Hariharan S, McBride MA, Cherikh WS, Tolleris CB, Bresnahan BA, Johnson CP. Posttransplant renal function in the first year predicts long-term kidney transplant survival. Kidney Int. juill 2002;62(1):311-8. 


\section{Tables and Figures}

Table 1: Description of recipients, donors, and transplantation characteristics of the studied population $(n=2749)$

\begin{tabular}{|c|c|c|}
\hline & Missing & Estimations \\
\hline \multicolumn{3}{|l|}{ Quantitative characteristics: mean \pm sd } \\
\hline Recipient age (years) & 0 & $49.7 \pm 13.6$ \\
\hline Recipient BMI (kg/m²) & 10 & $24.0 \pm 4.2$ \\
\hline Donor age (years) & 1 & $50.7 \pm 15.5$ \\
\hline Last donor $\mathrm{SCr}(\mu \mathrm{mol} / \mathrm{L})$ & 25 & $89.9 \pm 52.8$ \\
\hline Cold ischemia time (hours) & 10 & $17.8 \pm 9.8$ \\
\hline 3-month SCr $(\mu \mathrm{mol} / \mathrm{L})$ & 38 & $138.3 \pm 53.4$ \\
\hline 6-month SCr $(\mu \mathrm{mol} / \mathrm{L})$ & 75 & $136.6 \pm 53.2$ \\
\hline \multicolumn{3}{|l|}{ Categorical characteristics: N (\%) } \\
\hline Recipient men & 0 & $1674(60.9)$ \\
\hline Transplanted before 2008 & 0 & $1369(49.8)$ \\
\hline Second transplantation & 0 & $474(17.2)$ \\
\hline Dialysis technique & 3 & \\
\hline Pre-emptive transplantation & & $342(12.5)$ \\
\hline Hemodialysis & & $2192(79.8)$ \\
\hline Peritoneal dialysis & & $212(7.7)$ \\
\hline \multicolumn{3}{|l|}{ Time to dialysis prior to transplantation } \\
\hline (at least one year) & 36 & $1948(71.8)$ \\
\hline Recurrent causal nephropathy & 0 & $899(29.1)$ \\
\hline Diabetes history & 0 & $319(11.6)$ \\
\hline Hypertension history & 0 & $2272(82.6)$ \\
\hline Cardiovascular history & 0 & $933(33.9)$ \\
\hline History of dyslipidemia & 0 & $860(31.3)$ \\
\hline History of cancer & 0 & $228 \quad(8.3)$ \\
\hline HLA A-B-DR incompatibilities (>4) & 7 & $350(12.8)$ \\
\hline Positive anti-class I immunisation & 66 & $876(32.6)$ \\
\hline Positive anti-class II immunsation & 87 & $792(29.8)$ \\
\hline Donor men & 8 & $1545(56.4)$ \\
\hline Status & 6 & \\
\hline Living donor & & $418(15.2)$ \\
\hline Cerebrovascular donor death & & $1309(47.7)$ \\
\hline Non cerebrovascular donor death & & $1016(37.1)$ \\
\hline Delayed graft function & 15 & $714(26.1)$ \\
\hline Acute rejection episode during the first year & 0 & $591(21.5)$ \\
\hline
\end{tabular}

sd: standard deviation ; BMI: Body Mass Index; SCr: Serum Creatinine; HLA Human Leukocyte Antigen 
Table 2: Multivariable joint model for longitudinal evolution of logarithmic transformation of serum creatinine (SCr) and risk of graft failure (return to dialysis or death with a functioning graft) in kidney transplant patients ( $\mathrm{n}=2584$ patients, 165 patients excluded due to missing data)

\begin{tabular}{|c|c|c|c|c|c|c|c|c|c|}
\hline & \multicolumn{6}{|c|}{ Longitudinal process } & \multirow{2}{*}{\multicolumn{3}{|c|}{ Survival process }} \\
\hline & \multicolumn{3}{|c|}{$\begin{array}{c}\text { Association with the } \\
\log (1 \text {-year } \mathrm{SCr}) \text { (baseline effect) }\end{array}$} & \multicolumn{3}{|c|}{$\begin{array}{c}\text { Association with the } \\
\log (\mathrm{SCr} \text { evolution }) \text { (slope effect) }\end{array}$} & & & \\
\hline & coef & $95 \% \mathrm{CI}$ & $\mathrm{p}$-value & coef & $95 \% \mathrm{CI}$ & p-value & HR & $95 \% \mathrm{CI}$ & p-value \\
\hline Current $\mathrm{SCr}(\mu \mathrm{mol} / \mathrm{L})$, for an increase of $25 \%$ & & & & & & & 1.92 & {$[1.75 ; 2.11]$} & $<0.0001$ \\
\hline Current SCr increase $(\mu \mathrm{mol} / \mathrm{L})$, for a growth of $25 \%$ in 1 year & & & & & & & 1.89 & {$[1.17 ; 3.06]$} & 0.0097 \\
\hline Recipient age (years, standardized) & -0.028 & {$[-0.038 ;-0.018]$} & $<0.0001$ & -0.010 & {$[-0.014 ;-0.006]$} & $<0.0001$ & 1.51 & {$[1.35 ; 1.68]$} & $<0.0001$ \\
\hline Recipient gender: male vs female & 0.074 & {$[0.057 ; 0.091]$} & $<0.0001$ & -0.007 & {$[-0.014 ; 0.000]$} & 0.0392 & & & \\
\hline Diabetes history: yes vs no & 0.000 & {$[-0.026 ; 0.025]$} & 0.9866 & 0.027 & {$[0.016 ; 0.039]$} & $<0.0001$ & & & \\
\hline Cardiovascular history: yes vs no & 0.000 & {$[-0.017 ; 0.017]$} & 0.9812 & 0.008 & {$[0.000 ; 0.015]$} & 0.0371 & 1.39 & {$[1.14 ; 1.69]$} & 0.0011 \\
\hline 3-month $\mathrm{SCr}(\mu \mathrm{mol} / \mathrm{L}$, standardized $)$ & 0.083 & {$[0.071 ; 0.096]$} & $<0.0001$ & & & & 0.84 & {$[0.74 ; 0.95]$} & 0.0062 \\
\hline 6-month $\mathrm{SCr}(\mu \mathrm{mol} / \mathrm{L}$, standardized $)$ & 0.176 & {$[0.164 ; 0.189]$} & $<0.0001$ & & & & & & \\
\hline Acute rejection episode during the first year: yes vs no & 0.055 & {$[0.036 ; 0.074]$} & $<0.0001$ & & & & 1.46 & {$[1.17 ; 1.83]$} & 0.0010 \\
\hline Anti-class I immunization: positive vs negative & 0.010 & {$[-0.008 ; 0.027]$} & 0.2707 & 0.011 & {$[0.004 ; 0.019]$} & 0.0036 & 1.50 & {$[1.19 ; 1.90]$} & 0.0006 \\
\hline Rank of graft: second vs first & & & & & & & 1.32 & {$[1.02 ; 1.73]$} & 0.0381 \\
\hline Donor type (ref : living donor) & & & 0.0773 & & & 0.0022 & & & \\
\hline Cerebrovascular death & 0.028 & {$[0.004 ; 0.052]$} & & 0.018 & {$[0.007 ; 0.028]$} & & & & \\
\hline Non cerebrovascular death & 0.019 & {$[-0.005 ; 0.043]$} & & 0.010 & {$[-0.001 ; 0.020]$} & & & & \\
\hline Donor gender: male vs female & & & & & & & 0.83 & {$[0.69 ; 1.01]$} & 0.0589 \\
\hline Donor age (years, standardized) & 0.056 & {$[0.045 ; 0.066]$} & $<0.0001$ & & & & & & \\
\hline
\end{tabular}

Coef: coefficient; HR: Hazard Ratio; CI: confidence interval.

Referential value for 1 -year SCr was 4.024, 95\%CI: [3.982; 4.065]. Referential value for SCr evolution was 0.034 95\%CI: [0.018; 0.050]. This model is adjusted on a time effect with a threshold at 2008 (before 2008 vs after): coefficient for the relation to the SCr at 1 -year: $0.01895 \%$ CI: $[0.002 ; 0.034]$ and to the SCr evolution: $0.01395 \% \mathrm{CI}$ : [0.005; 0.020$]$ and HR = 0.73 [0.57; 0.94$]$. Parameters of the Weibull baseline risk function were: intercept $-20.247 \pm 0.982 ; \log ($ shape $): 0.337 \pm 0.046 . \alpha=2.93 ; \alpha_{2}=3.29$ 


\begin{tabular}{|c|c|c|c|c|c|c|}
\hline & \multicolumn{6}{|c|}{ Longitudinal process } \\
\hline & \multicolumn{3}{|c|}{$\begin{array}{l}\text { Association with the } \\
\log (1-y e a r \text { SCr) } \\
\text { (baseline effect) }\end{array}$} & \multicolumn{3}{|c|}{$\begin{array}{l}\text { Association with the } \\
\log (\text { SCr evolution) } \\
\text { (slope effect) }\end{array}$} \\
\hline & coef & $95 \% \mathrm{CI}$ & p-value & coef & $95 \% \mathrm{CI}$ & p-value \\
\hline Recipient age (years, standardized) & -0.025 & {$[-0.035 ;-0.015]$} & $<0.0001$ & -0.010 & {$[-0.013 ;-0.006]$} & $<0.0001$ \\
\hline Recipient gender: male vs female & 0.073 & {$[0.056 ; 0.090]$} & $<0.0001$ & -0.007 & {$[-0.013 ; 0.001]$} & 0.0441 \\
\hline History of diabetes: yes vs no & 0.003 & {$[-0.022 ; 0.028]$} & 0.7987 & 0.026 & {$[0.015 ; 0.038]$} & $<0.0001$ \\
\hline 3 month SCr $(\mu \mathrm{mol} / \mathrm{L}$, standardized $)$ & 0.085 & {$[0.072 ; 0.097]$} & $<0.0001$ & & & \\
\hline 6 month $\mathrm{SCr}(\mu \mathrm{mol} / \mathrm{L}$, standardized $)$ & 0.176 & {$[0.164 ; 0.189]$} & $<0.0001$ & & & \\
\hline Acute rejection episode $<1$ year: yes vs no & 0.055 & {$[0.036 ; 0.075]$} & $<0.0001$ & -0.009 & {$[-0.017 ;-0.001]$} & 0.0233 \\
\hline $\begin{array}{l}\text { Anti class I immunization: positive vs } \\
\text { negative }\end{array}$ & 0.010 & {$[-0.007 ; 0.028]$} & 0.2344 & 0.010 & {$[0.002 ; 0.017]$} & 0.0111 \\
\hline Donor age (years, standardized) & 0.057 & {$[0.046 ; 0.067]$} & $<0.0001$ & & & \\
\hline Cold ischemia time (hours) - standardized & 0.002 & {$[-0.006 ; 0.010]$} & 0.6717 & 0.004 & {$[0.001 ; 0.007]$} & 0.0253 \\
\hline
\end{tabular}

Coef: coefficient; CI: confidence interval ; $\mathrm{SCr}$ : serum creatinine

Referential value for 1 -year SCr was 4.024, 95\%CI : [3.985, 4.064]. Referential value for SCr evolution was 0.040 95\% CI: [0.025; 0.055].

This model is adjusted on a time effect with a threshold at 2008 (before 2008 vs after): coefficient for relation to the 1-year SCr: 0.020 95\%CI: [0.004; 0.037] and to the SCr evolution: $0.01195 \% \mathrm{CI}$ : [0.003;0.018]. 
Table 4: Multivariable time-dependent Cox model for patient-graft failure risk ( 2604 patients, 455 events observed).

\begin{tabular}{lrrr}
\hline & & \multicolumn{2}{c}{ Survival process } \\
& HR & 95\% CI & p-value \\
\hline Last observation of SCr carried forward $(\mathrm{LOCF}),(\mu \mathrm{mol} / \mathrm{L})$, & & & \\
$\quad$ for an increase of $25 \%$ & 2.07 & {$[1.97 ; 2.18]$} & $<0.0001$ \\
Recipient age (years, standardized) & 1.40 & {$[1.26 ; 1.55]$} & $<0.0001$ \\
Diabetes history: yes vs no & 1.50 & {$[1.15 ; 1.95]$} & 0.0031 \\
Cardiovascular history: yes vs no & 1.36 & {$[1.12 ; 1.65]$} & 0.0021 \\
3-month SCr $(\mu$ mol/L, standardized) & 0.80 & {$[0.73 ; 0.89]$} & $<0.0001$ \\
Anti class $I$ immunization: positive vs negative & 1.44 & {$[1.15 ; 1.81]$} & 0.0015 \\
Graft rank: second vs first & 1.37 & {$[1.05 ; 1.80]$} & 0.0221 \\
Donor gender: male vs female & 0.82 & {$[0.68 ; 1.00]$} & 0.0456 \\
Time to dialysis prior transplantation $(\geq 1$ year vs $<1)$ & 1.27 & {$[1.00 ; 1.60]$} & 0.0500 \\
\hline
\end{tabular}

HR: Hazard Ratio; CI: confidence interval ; $\mathrm{SCr}$ : serum creatinine

A period effect is included with a $\mathrm{HR}=0.7195 \% \mathrm{CI}[0.55 ; 0.92]$ 
Table S1: Multivariable joint model for longitudinal evolution of logarithmic transformation of serum creatinine (SCr) and risk of graft loss (return to dialysis, while death with a functioning graft is censored) in kidney transplant patients ( $\mathrm{n}=2584$ patients, 165 patients excluded due to missing data, 259 events observed)

\begin{tabular}{|c|c|c|c|c|c|c|c|c|c|}
\hline & \multicolumn{6}{|c|}{ Longitudinal process } & \multirow{2}{*}{\multicolumn{3}{|c|}{ Survival process }} \\
\hline & \multicolumn{3}{|c|}{$\begin{array}{c}\text { Association with the } \\
\log (1 \text {-year SCr) (baseline effect) }\end{array}$} & \multicolumn{3}{|c|}{$\begin{array}{l}\text { Association with the } \\
\log (\mathrm{SCr} \text { evolution) (slope effect) }\end{array}$} & & & \\
\hline & coef & $95 \% \mathrm{CI}$ & p-value & coef & $95 \% \mathrm{CI}$ & p-value & HR & $95 \% \mathrm{CI}$ & p-value \\
\hline Current $\mathrm{SCr}(\mu \mathrm{mol} / \mathrm{L})$, for an increase of $25 \%$ & & & & & & & 2.51 & {$[2.22 ; 2.84]$} & $<0.0001$ \\
\hline Current SCr increase $(\mu \mathrm{mol} / \mathrm{L})$, for a growth of $25 \%$ in 1 year & & & & & & & 2.87 & {$[1.58 ; 5.22]$} & 0.0005 \\
\hline Recipient age (years, standardized) & -0.028 & {$[-0.038 ;-0.017]$} & $<0.0001$ & -0.011 & {$[-0.015 ;-0.007]$} & $<0.0001$ & 1.20 & {$[1.05 ; 1.39]$} & 0.0096 \\
\hline Recipient gender: male vs female & 0.074 & {$[0.057 ; 0.091]$} & $<0.0001$ & -0.008 & {$[-0.015 ;-0.001]$} & 0.0176 & & & \\
\hline Diabetes history: yes vs no & 0.000 & {$[-0.026 ; 0.025]$} & 0.9939 & 0.026 & {$[0.015 ; 0.038]$} & $<0.0001$ & & & \\
\hline Cardiovascular history: yes vs no & 0.001 & {$[-0.017 ; 0.018]$} & 0.9494 & 0.007 & {$[-0.001 ; 0.014]$} & 0.0729 & 1.07 & {$[0.81 ; 1.41]$} & 0.6531 \\
\hline 3-month $\mathrm{SCr}(\mu \mathrm{mol} / \mathrm{L}$, standardized $)$ & 0.083 & {$[0.071 ; 0.096]$} & $<0.0001$ & & & & 0.85 & {$[0.73 ; 0.98]$} & 0.0285 \\
\hline 6-month $\mathrm{SCr}(\mu \mathrm{mol} / \mathrm{L}$, standardized $)$ & 0.176 & {$[0.164 ; 0.189]$} & $<0.0001$ & & & & & & \\
\hline Acute rejection episode during the first year: yes vs no & 0.055 & {$[0.045 ; 0.066]$} & $<0.0001$ & & & & 1.63 & {$[1.20 ; 2.20]$} & 0.0016 \\
\hline Anti-class I immunization: positive vs negative & 0.010 & {$[-0.007 ; 0.028]$} & 0.2414 & 0.011 & {$[0.003 ; 0.019]$} & 0.0062 & 1.50 & {$[1.09 ; 2.07]$} & 0.0127 \\
\hline Rank of graft: second vs first & & & & & & & 1.56 & {$[1.09 ; 2.23]$} & 0.0158 \\
\hline Donor type (ref : living donor) & & & 0.0742 & & & 0.0019 & & & \\
\hline Cerebrovascular death & 0.028 & {$[0.004 ; 0.052]$} & & 0.017 & {$[0.007 ; 0.028]$} & & & & \\
\hline Non cerebrovascular death & 0.019 & {$[-0.005 ; 0.044]$} & & 0.010 & {$[-0.001 ; 0.020]$} & & & & \\
\hline Donor gender: male vs female & & & & & & & 0.92 & {$[0.70 ; 1.21]$} & 0.554 \\
\hline Donor age (years, standardized) & 0.055 & {$[0.045 ; 0.066]$} & $<0.0001$ & & & & & & \\
\hline
\end{tabular}

Coef: coefficient; HR: Hazard Ratio; CI: confidence interval

Referential value for 1-year SCr was 4.022, 95\%CI: [3.980; 4.064]. Referential value for SCr evolution was 0.039 95\%CI: [0.023; 0.055]. This model is adjusted on a time effect with a threshold at 2008 (before 2008 vs after): coefficient for the relation to the 1 -year SCr: $0.01995 \%$ CI: $[0.002 ; 0.035]$ and to the SCr evolution: $0.01295 \%$ CI: $[0.004 ; 0.020]$ and HR $=0.73[0.57 ; 0.93]$. Parameters of the Weibull baseline risk function were: intercept $-26.665 \pm 1.335 ; \log ($ (shape): $0.2987 \pm$ $0.066 . \alpha=4.12 ; \alpha_{2}=5.45$ 
Table S2: Multivariable joint model for longitudinal evolution of logarithmic transformation of serum creatinine (SCr) and risk of death with a functioning graft (return to dialysis is censored) in kidney transplant patients (n=2584 patients, 165 patients excluded due to missing data, 198 events observed)

\begin{tabular}{|c|c|c|c|c|c|c|c|c|c|}
\hline & \multicolumn{6}{|c|}{ Longitudinal process } & \multirow{2}{*}{\multicolumn{3}{|c|}{ Survival process }} \\
\hline & \multicolumn{3}{|c|}{$\begin{array}{c}\text { Association with the } \\
\log (1 \text {-year SCr) (baselyne effect) }\end{array}$} & \multicolumn{3}{|c|}{$\begin{array}{c}\text { Association with the } \\
\log (\mathrm{SCr} \text { evolution) (slope effect) }\end{array}$} & & & \\
\hline & coef & $95 \% \mathrm{CI}$ & p-value & coef & $95 \% \mathrm{CI}$ & p-value & HR & $95 \% \mathrm{CI}$ & p-value \\
\hline Current $\mathrm{SCr}(\mu \mathrm{mol} / \mathrm{L})$, for an increase of $25 \%$ & & & & & & & 1.47 & {$[1.24 ; 1.74]$} & $<0.0001$ \\
\hline Current SCr increase $(\mu \mathrm{mol} / \mathrm{L})$, for a growth of $25 \%$ in 1 year & & & & & & & 0.31 & {$[0.09 ; 0.97]$} & 0.0559 \\
\hline Recipient age (years, standardized) & -0.028 & {$[-0.038 ;-0.018]$} & $<0.0001$ & -0.011 & {$[-0.015 ;-0.007]$} & $<0.0001$ & 2.36 & {$[1.95 ; 2.86]$} & $<0.0001$ \\
\hline Recipient gender: male vs female & 0.074 & {$[0.057 ; 0.091]$} & $<0.0001$ & -0.008 & {$[-0.015 ;-0.002]$} & 0.0163 & & & \\
\hline Diabetes history: yes vs no & 0.002 & {$[-0.023 ; 0.027]$} & 0.8757 & 0.024 & {$[0.013 ; 0.036]$} & $<0.0001$ & & & \\
\hline Cardiovascular history: yes vs no & 0.000 & {$[-0.017 ; 0.017]$} & 0.9719 & 0.006 & {$[-0.001 ; 0.013]$} & 0.1038 & 2.01 & {$[1.49 ; 2.70]$} & $<0.0001$ \\
\hline 3-month SCr $(\mu \mathrm{mol} / \mathrm{L}$, standardized $)$ & 0.084 & {$[0.072 ; 0.096]$} & $<0.0001$ & & & & 0.78 & {$[0.62 ; 0.98]$} & 0.0331 \\
\hline 6-month $\mathrm{SCr}(\mu \mathrm{mol} / \mathrm{L}$, standardized $)$ & 0.175 & {$[0.163 ; 0.187]$} & $<0.0001$ & & & & & & \\
\hline Acute rejection episode during the first year: yes vs no & 0.054 & {$[0.035 ; 0.073]$} & $<0.0001$ & & & & 1.24 & {$[0.86 ; 1.80]$} & 0.2428 \\
\hline Anti-class I immunization: positive vs negative & 0.010 & {$[-0.008 ; 0.027]$} & 0.2753 & 0.010 & {$[0.002 ; 0.018]$} & 0.0094 & 1.55 & {$[1.10 ; 2.21]$} & 0.0135 \\
\hline Rank of graft: second vs first & & & & & & & 1.17 & {$[0.78 ; 1.76]$} & 0.4401 \\
\hline Donor type (ref : living donor) & & & 0.0675 & & & 0.0028 & & & \\
\hline Cerebrovascular death & 0.028 & {$[0.004 ; 0.052]$} & & 0.017 & {$[0.007 ; 0.027]$} & & & & \\
\hline Non cerebrovascular death & 0.019 & {$[-0.005 ; 0.043]$} & & 0.009 & {$[-0.001 ; 0.019]$} & & & & \\
\hline Donor gender: male vs female & & & & & & & 0.72 & {$[0.54 ; 0.95]$} & 0.0209 \\
\hline Donor age (years, standardized) & 0.056 & {$[0.046 ; 0.067]$} & $<0.0001$ & & & & & & \\
\hline
\end{tabular}

Coef: coefficient; HR: Hazard Ratio; CI: confidence interval.
Referential value for 1-year SCr was 4.024, 95\%CI: [3.982; 4.065]. Referential value for SCr evolution was 0.037 95\%CI: [0.021; 0.053$]$. This model is adjusted on a time effect with a threshold at 2008 (before 2008 Referential value for 1 -year SCr was 4.024, $95 \%$ CI: [3.982; 4.065]. Referential value for SCr evolution was $0.03795 \%$ CI: $[0.021 ; 0.053]$. This model is adjusted on a time effect with a threshold at 2008 (before 2008
vs after): coefficient for the relation to the 1 -year SCr: $0.02095 \%$ CI: [0.004; 0.036$]$ and to the SCr evolution: $0.01295 \%$ CI: $[0.004 ; 0.019]$ and HR $=0.76$ [0.53; 1.11$]$. Parameters of the Weibull baseline risk function were: intercept $-16.381 \pm 1.723 ; \log \left(\right.$ shape): $0.4225 \pm 0.062 . \alpha=1.72 ; \alpha_{2}=-6.12$ 
Fig. 1: Patient and graft survival according to the time since the first anniversary of the transplantation $(n=2749)$ from KaplanMeier estimator and their corresponding 95\% confidence interval

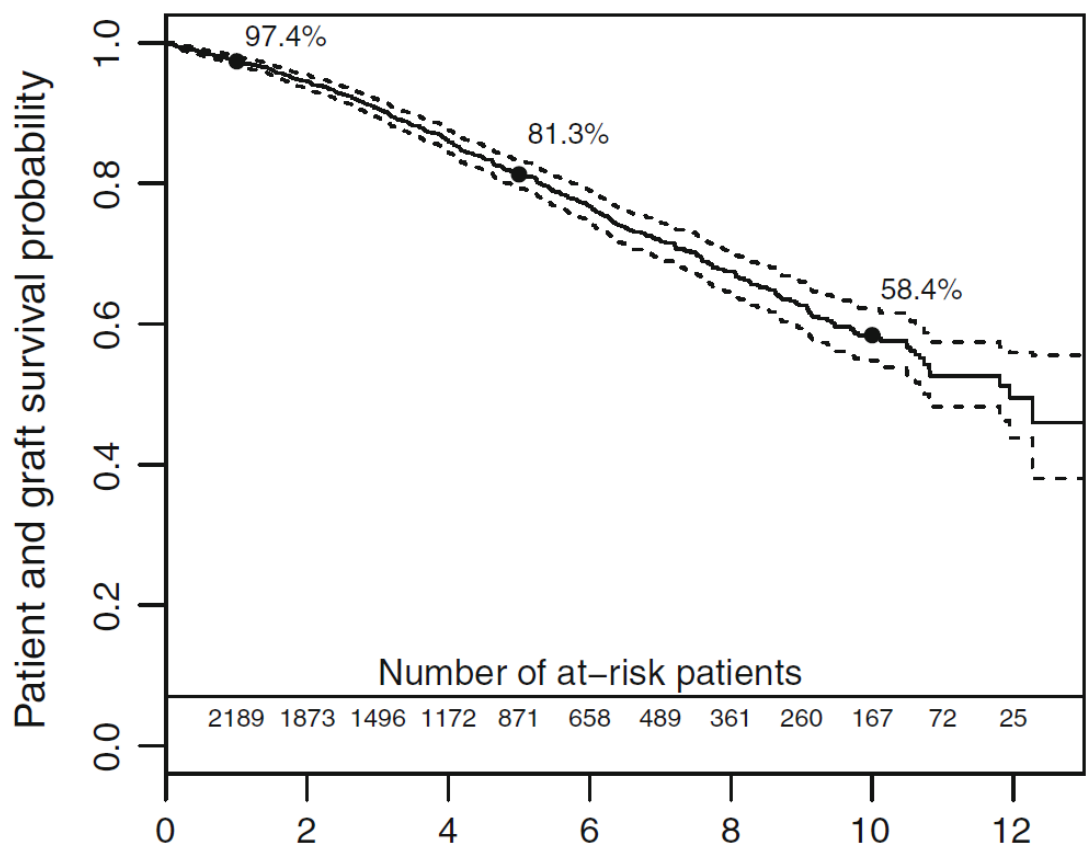

Time since the first anniversary of transplantation (years) 


\section{Appendix 1: Mathematical formulation of the shared random effect joint model}

Let $\mathrm{Y}$ be the longitudinal marker and $t_{i j}$ the time of measurement of the $j^{\text {th }}\left(j=1, \ldots, n_{i}\right)$ measure for the patient $i$ $(i=1, \ldots, N)$. Let $h($.$) denotes the instantaneous risk function of graft failure. The joint model combines a linear$ mixed model (equation 1) with a parametric regression model (equation 2). They share the random effects $\left(\mathrm{b}_{0 \mathrm{i}} ; \mathrm{b}_{1 \mathrm{i}}\right)$

$$
\left\{\begin{array}{l}
Y_{i j}\left(t_{i j}\right)=\left(\beta_{0}+b_{0 i}\right)+\left(\beta_{1}+b_{1 i}\right) t_{i j}+\beta_{2} X_{1 i}+\beta_{3} X_{2 i} t_{i j}+\varepsilon_{i j} \\
h_{i}(t)=h_{0}(t) \exp \left(\gamma^{T} X_{3 i}+g\left(m_{i}(t) ; \alpha\right)\right)
\end{array}\right.
$$

with $\left(\mathrm{b}_{0 \mathrm{i}} ; \mathrm{b}_{1 \mathrm{i}}\right)^{\mathrm{T}} \sim \mathrm{MVN}(0, \mathrm{~B})$, B an unstructured variance-covariance matrix, $\mathrm{X}_{1 \mathrm{i}}$ a vector of baseline covariates influencing the baseline value of longitudinal marker, $\mathrm{X}_{2 \mathrm{i}}$ another vector of baseline covariates that may change marker evolution over time and $\beta_{0}, \beta_{1}$ two scalars defining the referential value of the baseline level and the slope of the longitudinal biomarker $Y$ (.) respectively, and $\beta_{2}, \beta_{3}$ two p-vectors of the same dimension as $X_{1}$ and $\mathrm{X}_{2}$ respectively. The evolution of the measurements $\mathrm{Y}_{\mathrm{ij}}\left(\mathrm{t}_{\mathrm{ij}}\right)$ are defined by the sum of a subject specific trend $\mathrm{m}_{\mathrm{i}}\left(\mathrm{t}_{\mathrm{ij}}\right)$ plus an error term $\varepsilon_{\mathrm{ij}} \sim \mathrm{N}\left(0, \sigma_{\varepsilon}^{2}\right)$. For the instantaneous risk function of graft failure, $\mathrm{h}_{0}(\mathrm{t})$ denotes the baseline risk function, and $\mathrm{X}_{3 \mathrm{i}}$ is a vector of baseline covariates that could influence the graft failure risk, with a corresponding vector of fixed regression coefficients $\gamma . \mathrm{g}$ is a function of the true level of the marker $\mathrm{m}_{\mathrm{i}}$, which specifies the type of dependence between the longitudinal and the survival processes. Classically, it may be the current level of the marker $\left(g\left(m_{i}(t)\right)=\alpha m_{i}(t)\right)$, the intensity of marker deterioration during the follow-up i.e. the slope $\left(\mathrm{g}\left(\mathrm{m}_{\mathrm{i}}(\mathrm{t})\right)=\alpha_{2} \mathrm{~m}_{\mathrm{i}}{ }^{\prime}(\mathrm{t})\right)$, or both $\left(\mathrm{g}\left(\mathrm{m}_{\mathrm{i}}(\mathrm{t})\right)=\alpha_{1} \mathrm{~m}_{\mathrm{i}}(\mathrm{t})+\alpha_{2} \mathrm{~m}_{\mathrm{i}}{ }^{\prime}(\mathrm{t})\right)(2)$. This latter is the retained association of the model presented in table 2 . 


\section{Appendix 2: Clinical interpretations of the joint model parameters}

\section{1/ Parameters of the longitudinal process}

Due to the log transformation of the longitudinal marker SCr, the parameters in the linear mixed submodel should be interpreted as the log of relative change. The longitudinal equation can be written as follows:

$$
\log \left(\operatorname{SCr}\left(t_{i j}\right)\right)=\beta_{0}+b_{0 i}+\left(\beta_{1}+b_{1 i}\right) t_{i j}+\beta_{2} X_{1 i}+\beta_{3} X_{2 i} t_{i j}
$$

and the SCr evolution can be re-written as:

$$
\operatorname{SCr}\left(t_{i j}\right)=\exp \left(\beta_{0}+b_{0 i}\right) \exp \left(\left(\beta_{1}+b_{1 i}\right) t_{i j}\right) \exp \left(\beta_{2} X_{1 i}\right) \exp \left(\beta_{3} X_{2 i} t_{i j}\right)
$$

2.1.1/ Qualitative variables:

Let $\mathrm{Z}$ be a qualitative variable associated with:

- $\quad$ the 1-year SCr only $\left(\mathrm{Z} \subseteq \mathrm{X}_{1} ; \mathrm{Z} \mathscr{\mathrm { X }} 2\right)$ ). The excess of $\mathrm{SCr}$ for a patient with $\mathrm{Z}=1$ as compared to the case where $\mathrm{Z}=0$ for the same patient is:

$\operatorname{SCr}\left(t_{i j}\right)_{\left[z_{i}=1 v s z_{i}=0\right]}=\frac{\left.\exp \left(\beta_{0}+b_{0 i}\right) \exp \left(\left(\beta_{1}+b_{1 i}\right) t_{i j}\right) \exp \left(\beta_{2}\right)\right)}{\exp \left(\beta_{0}+b_{0 i}\right) \exp \left(\left(\beta_{1}+b_{1 i}\right) t_{i j}\right)}$

$\operatorname{SCr}\left(\mathrm{t}_{\mathrm{ij}}\right)_{\left[\mathrm{Z}_{\mathrm{i}}=1 \text { vs } \mathrm{Z}_{\mathrm{i}}=0\right]}=\exp \left(\beta_{2}\right)$

This gap of SCr is constant beyond 1-year post-transplantation.

- $\quad$ both the 1-year $\mathrm{SCr}$ and the $\mathrm{SCr}$ increase during the follow-up $\left(\mathrm{Z} \subseteq \mathrm{X}_{1} ; \mathrm{Z} \subseteq \mathrm{X}_{2}\right)$

$\operatorname{SCr}\left(t_{i j}\right)_{\left[Z_{i}=1 \text { vs } Z_{i}=0\right]}=\exp \left(\beta_{2}+\beta_{3} t_{i j}\right)$

This gap of SCr value is increasing or decreasing during the follow-up according to the sign of $\beta_{3}$. For clinical purposes, in the interpretations, we used the time $t=5$ to quantify a relative change at 5 years after the first year post-transplantation.

\subsection{2/ Quantitative variables:}

Let $\mathrm{W}_{1}$ be a quantitative variable with $\mathrm{sd}_{\mathrm{W} 1}$ its standard deviation, $\mathrm{w}$ a value of $\mathrm{W}_{1}$ and $\Delta$ a relevant clinical increase. 
- $\quad$ Let $\mathrm{X}_{1}$ be the standardized version of $\mathrm{W}_{1}, \mathrm{X}_{2}$ be null ( $\mathrm{W}_{1}$ was associated with the 1-year SCr only).

$$
\begin{aligned}
\operatorname{SCr}\left(t_{\mathrm{ij}}\right)\left[\mathrm{W}_{1 \mathrm{i}}=\mathrm{w}+\Delta \mathrm{vs} \mathrm{W}_{1 \mathrm{i}}^{\prime}=\mathrm{w}\right] & =\frac{\exp \left(\beta_{0}+\mathrm{b}_{0 \mathrm{i}}\right) \exp \left(\left(\beta_{1}+\mathrm{b}_{1 \mathrm{i}}\right) \mathrm{t}_{\mathrm{ij}}\right) \exp \left(\beta_{2}\left(\frac{(\mathrm{w}+\Delta)}{\mathrm{sd}_{\mathrm{W} 1}}\right)\right)}{\exp \left(\beta_{0}+\mathrm{b}_{0 \mathrm{i}}\right) \exp \left(\left(\beta_{1}+\mathrm{b}_{1 \mathrm{i}}\right) \mathrm{t}_{\mathrm{ij}}\right) \exp \left(\beta_{2}\left(\mathrm{w} / \mathrm{sd}_{\mathrm{W} 1}\right)\right)} \\
& =\frac{\exp \left(\beta_{2} \mathrm{w} / \mathrm{sd}_{\mathrm{W} 1}+\beta_{2} \Delta / \mathrm{sd}_{\mathrm{W} 1}\right)}{\exp \left(\beta_{2}\left(\mathrm{w} / \mathrm{sd}_{\mathrm{W} 1}\right)\right)} \\
& =\exp \left(\beta_{2} \Delta / \mathrm{sd}_{\mathrm{W} 1}\right)
\end{aligned}
$$

- Now, let $\mathrm{X}_{1}=\mathrm{X}_{2}$ be the standardized version of $\mathrm{W}_{1}\left(\mathrm{~W}_{1}\right.$ was associated with both the 1-year $\mathrm{SCr}$ and the $\mathrm{SCr}$ evolution).

$$
\begin{aligned}
\operatorname{sCr}\left(t_{i j}\right)\left[W_{1 i}=w+\Delta v s W_{1 i}^{\prime}=w\right] & =\frac{\exp \left(\beta_{0}+b_{0 i}\right) \exp \left(\left(\beta_{1}+b_{1 i}\right) t_{i j}\right) \exp \left(\beta_{2}\left(\frac{(w+\Delta)}{s d_{W 1}}\right)\right) \exp \left(\beta_{3} t_{i j}\left(\frac{(w+\Delta)}{s d_{W 1}}\right)\right)}{\exp \left(\beta_{0}+b_{0 i}\right) \exp \left(\left(\beta_{1}+b_{1 i}\right) t_{i j}\right) \exp \left(\beta_{2}\left(w / s d_{W 1}\right)\right) \exp \left(\beta_{3} t_{i j}\left(w / s d_{W 1}\right)\right)} \\
& \left.=\exp \left(\beta_{2} \Delta / s_{W 1}\right) \exp \left(\beta_{3} t_{i j} \Delta / s_{W 1}\right)\right)
\end{aligned}
$$

\section{2/ Hazard ratio for the longitudinal marker}

As we have seen in appendix 1, the instantaneous risk function is written as follows:

$$
\begin{aligned}
\mathrm{h}_{\mathrm{i}}(\mathrm{t}) & =\mathrm{h}_{0}(\mathrm{t}) \exp \left(\gamma^{\mathrm{T}} \mathrm{X}_{3 \mathrm{i}}+\alpha_{1} \mathrm{~m}_{\mathrm{i}}(\mathrm{t})+\alpha_{2} \mathrm{~m}_{\mathrm{i}}{ }^{\prime}(\mathrm{t})\right) \\
& =\mathrm{h}_{0}(\mathrm{t}) \exp \left(\gamma^{\mathrm{T}} \mathrm{X}_{3 \mathrm{i}}+\alpha_{1} \mathrm{~m}_{\mathrm{i}}(\mathrm{t})+\alpha_{2} \frac{\delta \mathrm{m}_{\mathrm{i}}(\mathrm{t})}{\delta \mathrm{t}}\right)
\end{aligned}
$$

With $\mathrm{m}_{\mathrm{i}}(\mathrm{t})=\beta_{0 \mathrm{i}}+\beta_{1 \mathrm{i}} \mathrm{t}$ and $\frac{\delta \mathrm{m}_{\mathrm{i}}(\mathrm{t})}{\delta \mathrm{t}}=\beta_{1 \mathrm{i}}$

As we use a $\log$ transformation of $\mathrm{SCr}$ measurement $(\mathrm{Y}(\mathrm{t})=\log (\mathrm{SCr}(\mathrm{t})))$, the hazard ratio which quantifies the association between the longitudinal marker and the risk of event was expressed for a clinically relevant difference.

- $\quad$ For the current level of the marker, we can rewrite the HR for a difference of $25 \%$ in $\mathrm{SCr}$ values at the same time for the same patient and the same slope:

$$
\begin{aligned}
\mathrm{HR}_{1.25 \operatorname{SCr}(\mathrm{t}) \mathrm{vs} \mathrm{SCr}(\mathrm{t})} & =\frac{\mathrm{h}_{0}(\mathrm{t}) \exp \left(\gamma^{\mathrm{T}} \mathrm{X}_{3 \mathrm{i}}+\alpha_{1} \log (1.25 \operatorname{SCr}(\mathrm{t}))+\alpha_{2} \mathrm{~m}_{\mathrm{i}}{ }^{\prime}(\mathrm{t})\right)}{\mathrm{h}_{0}(\mathrm{t}) \exp \left(\gamma^{\mathrm{T}} \mathrm{X}_{3 \mathrm{i}}+\alpha_{1} \log (\operatorname{SCr}(\mathrm{t}))+\alpha_{2} \mathrm{~m}_{\mathrm{i}}{ }^{\prime}(\mathrm{t})\right)} \\
& =\exp \left(\alpha_{1}(\log (1.25 \operatorname{SCr}(\mathrm{t}))-\log (\operatorname{SCr}(\mathrm{t})))\right) \\
& =1.25^{\alpha_{1}}
\end{aligned}
$$


- For the intensity of the marker, the HR which compares the situation in which $\frac{\delta}{\delta \mathrm{t}} \log \left(\mathrm{SCr}_{\mathrm{i}}(\mathrm{t})\right)=\mathrm{s}_{1}$ to another in which $\frac{\delta}{\delta \mathrm{t}} \log \left(\mathrm{SCr}_{\mathrm{i}}(\mathrm{t})\right)=\mathrm{s}_{2}$, for same covariates $\mathrm{X}_{3 \mathrm{i}}$ and level of $\mathrm{SCr}$ at time $\mathrm{t}$ is equal. $\mathrm{HR}=\exp \left(\alpha_{2}\left(s_{2}-s_{1}\right)\right)$

Besides, because we assume a linear model, $\frac{\delta}{\delta \mathrm{t}} \log \left(\mathrm{SCr}_{\mathrm{i}}(\mathrm{t})\right)$ is constant, that is $\forall \mathrm{t}, \frac{\delta}{\delta \mathrm{t}} \log \left(\mathrm{SCr}_{\mathrm{i}}(\mathrm{t})\right)=\mathrm{s}$ for some $s \in \mathbb{R}$. This implies $\forall \mathrm{t}^{\prime}>\mathrm{t}$ :

$$
\operatorname{SCr}_{i}\left(t^{\prime}\right)=\operatorname{SCr}_{i}(t) \exp \left(s\left(t^{\prime}-t\right)\right)
$$

If the SCr increases by $\mathrm{x} \%$ between $\mathrm{t}-1$ and $\mathrm{t}$, then $\mathrm{s}=\log (1+\mathrm{x} / 100)$ because $\mathrm{s}=\log \left(\frac{\mathrm{SCr}(\mathrm{t})}{\mathrm{SCr}_{i}(\mathrm{t}-1)}\right)$

This leads to: $\mathrm{HR}=\exp \left(\alpha_{2}(\log (1+\mathrm{x} / 100)-\log (1+\mathrm{y} / 100))\right)$ which is the HR which compares an increase of $\mathrm{x} \%$ between $\mathrm{t}-1$ and $\mathrm{t}$ to an increase of $\mathrm{y} \%$. In our paper, we choose to compare an increase of $25 \%$ compare to the mean evolution (a growth of $3 \%$ each year).

\section{3/ Hazard ratio for the quantitative variables}

Because the quantitative variables have been standardized, the HR for these factors were expressed for an increase of one standard deviation. In order to calculate them for an increase of relevant threshold in the variable unit, we can proceed as follows:

Let $\mathrm{X}_{1}$ be the standardization of $\mathrm{W}_{1}$ with $\mathrm{sd}_{1}$ its standard deviation. $\mathrm{HR}_{\mathrm{X}}$ is the HR obtained for the standardized variable and $\mathrm{HR}_{\mathrm{W}}$ is the one for an increase of $\Delta$ unit of $\mathrm{W}_{1}$.

$$
\mathrm{HR}_{W}=\mathrm{HR}_{\mathrm{X}}\left(\frac{\Delta}{\mathrm{sd}_{1}}\right)
$$

